\title{
Efficacy of using Zaontz urethral stent in hypospadias repair by the Face, Legs, Activity, Cry, Consolability (FLACC) scale: A prospective study
}

\author{
Serkan Ozcan, MD;i Murat Bagcioglu, MD, ${ }^{2}$ Tolga Karakan, MD,3 Mehmet Akif Diri, MD,; Arif Demirbas, MD \\ 'Artvin State Hospital, Urology Department, Artvin, Turkey; ${ }^{2}$ Kafkas University, Faculty of Medicine, Urology Department, Kars, Turkey; ${ }^{3}$ Ankara Training and Research Hospital, Urology Department, Ankara, Turkey
}

Cite as: Can Urol Assoc J 2017;11(1-2):E15-8. hrtp://dx.doi.org/10.5489/cuai.3944 Published online January 12, 2017

\section{Abstract}

Introduction: The developments in hypospadias surgical techniques and materials are intended to improve surgery outcomes and patient comfort. The aim of this study is to determine the effect of the Zaontz urethral stent (ZUS) (Cook Medical) on patient comfort and surgical success rates in children undergoing hypospadias surgery.

Methods: A feeding tube was used to repair 46 cases of primary distal hypospadias, and ZUS $(6 \mathrm{~F}, 8 \mathrm{~F}$, and $10 \mathrm{~F}$ in diameter) was used to repair to 31 cases of primary distal hypospadias between December 2009 and June 2011 in our clinic. ZUS was compared with the feeding tube in terms of surgical success rates and patient comfort in assessments made during postoperative periods.

Results: The patients with ZUS were followed with a stent for seven days postoperatively, as were the patients with the feeding tube. There was no statistical difference between the two groups in terms of fistula formation ( $p>0.05)$. Patient comfort was evaluated by the Face, Legs, Activity, Cry, Consolability (FLACC) scale on the first and third postoperative days, and a statistically significant difference was observed in favour of ZUS on the third postoperative day $(p<0.05)$.

Conclusions: Compared with a feeding tube in hypospadias repair, ZUS does not make any contribution to the urinary fistula rates. However, ZUS may have an advantage in terms of patient comfort in the postoperative followup. On the other hand, the small number of patients and the high price of the ZUS were the most important limitations. Prospective, randomized trials are needed to assess efficacy and cost.

\section{Introduction}

Hypospadias is when the urethral meatus opens abnormally at any point from the ventral side of the glans penis to the perineum. Hypospadias is one of the most common genital anomalies in pediatric urology, with incidence of approxi- mately 1 in 300 live male births. In most cases, it is located in the distal urethra. ${ }^{1}$ Many surgical techniques have been described, and the use of catheters during surgery has often been suggested. The aim of urinary diversion is to provide immobility of the suture line, to drain the bladder and the newly created urethra, and to reduce tissue reaction. ${ }^{2}$ The most common problems related to catheter use are infection, catheter obstruction, bladder spasms, and traumatization during insertion and removal of the catheter. ${ }^{3}$ In clinical practice, latex, silicone, silastic, polyvinyl chloride, polyethylene, and antimicrobial catheters are used. ${ }^{4,5}$ Zaontz urethral stent (ZUS) (Cook Medical) (Fig. 1) is one such catheter. The aim of our study is to evaluate the rates of patient comfort and surgical success of ZUS, which is used with the tubularized incised-plate urethroplasty (TIPU) method in hypospadias repair in our clinic.

\section{Methods}

A feeding tube was used to repair 46 cases of primary distal hypospadias, and ZUS (6F, 8F, and $10 \mathrm{~F}$ in diameter) was used to repair 31 cases between December 2009 and June 2011 in our clinic. This method was used in patients whose urethral meatus localization were coronal, subcoronal, and distal penile. The patients with secondary and proximal hypospadias were excluded from the study.

The procedure was performed under general anesthesia in all cases, and the technique described by Snodgrass was used. The feeding tube was pushed into the bladder from the urethral meatus, and ZUS was pushed into the external sphincter region. The suspended suture was transversely anchored with $4 / 0$ Vicryl on the glans penis. Then, the tissue that would form a $1.5 \mathrm{~cm}$ long tube was marked with a skin marker so that the circumference of the tube would be the diameter. It was also marked alongside the circumcision line at the subcoronal level. Then, the incision was made with a scalpel at the marked points.

After the skin was incised at the circumcision line, the suspended sutures were anchored with 4/0 Vicryl on the 


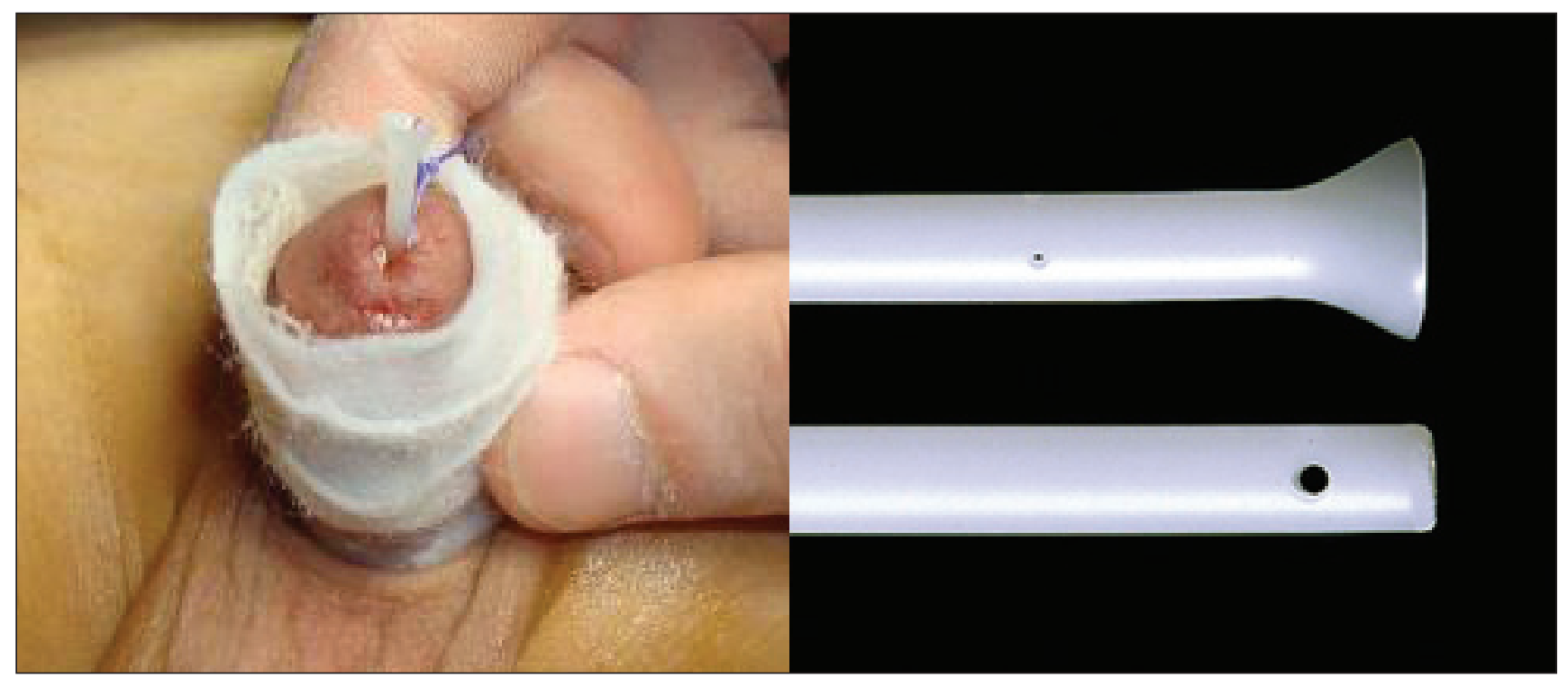

Fig. 1. View of Zaontz urethral stent and its placement after hypospaias repair.

skin. After the subcutaneous tissues were released with sharp dissections, the bottom of the newly formed tube was incised with a scalpel. It was tubularized with a continuous suture pattern from distal to proximal and starting from the glanular level with 5/0 PDS around the released tube. The urethral meatus was brought to the glandular level. Glans leaves were closed by individually suturing with two coats on the tube formed by $4 / 0$ Vicryl. A compression bandage was applied to the penis, and the treatment was ended.

ZUS was compared with the feeding tube in terms of patient comfort in assessments made during postoperative periods. This comparison was evaluated by the Face, Legs, Activity, Cry, Consolability (FLACC) scale (Fig. 2). This scale was previously evaluated by many scales, such as the analgesia/nociception index (ANI) and COMFORT-behaviour scale, and it was found to be successful (Fig. 2).$^{6-8}$ The patients were controlled in terms of fistula formation and urethral meatus stenosis on the 15th day and the six months postoperatively.

The study was approved by Ethics Committee of Kafkas University. The findings were statistically evaluated by the Mann-Whitney $U$ test. All analyses were performed using IBM SPSS v22 (IBM SPSS Inc., Armonk, NY, U.S.) with statistical significance assessed at the $5 \%$ level.

\section{Results}

The 77 patients included in the study were randomized and divided into two groups. Coin-flipping was used for randomization. ZUS was used for 31 patients and the feeding tube was used for 46 patients during distal hypospadias repair. The average age was $3.38 \pm 0.12$ years. The patients with ZUS were followed with a stent for seven days postoperatively, as were the patients with the feeding tube. Fistula formation was observed in three (6.5\%) patients on the 15th day and in seven $(15.2 \%)$ patients in the sixth month in the feeding tube group. The respective numbers of cases were two $(6.4 \%)$ and five $(16.1 \%)$ in the ZUS group.

There was no statistical difference between the two groups in terms of fistula formation $(p>0.05)$. Furthermore, meatal stenosis was found in one $(3.2 \%)$ patient in the ZUS group and in two $(4.3 \%)$ patients in feeding tube group in the sixth month, but there was no statistical difference between groups in terms of meatal stenosis ( $p>0.05)$. Pain assessment was made with the FLACC scale, but there was no statistical difference between groups on the first postoperative day. A statistically significant difference was observed in favour of ZUS on the third postoperative day $(p<0.05)$ (Table 1$)$.

\section{Discussion}

Anthyllis is known as the first surgeon to perform hypospadias surgery. Galen emphasized the importance of chordee. Today, many surgeons, such as Duckett have reported a number of techniques. Many modifications have been made and different types of catheters used. ${ }^{9}$ Most pediatric urologists suggest a stent for five or seven days postoperatively in order to reduce the complication rates, but it was observed that some do not prefer catheters because of infection, pain, bladder spasms, and trauma during removal. ${ }^{10,11}$

Successful results in hypospadias repair are impacted by the selection of an appropriate surgical technique, the length of the newly formed urethra, the suture technique, postoperative care, and the selection of urinary diversion. ${ }^{12}$ Some articles suggest that distal hypospadias surgery should be made without diversion and claim that the use of the stent is unnecessary, but we believe that the diversion still needs 


\begin{tabular}{|c|c|c|c|}
\hline \multicolumn{4}{|c|}{ Face, Legs, Activity, Cry, Consolability (FLACC) scale } \\
\hline Face & $\begin{array}{c}0 \\
\text { No particular } \\
\text { expression or smile }\end{array}$ & $\begin{array}{c}1 \\
\text { Occasional grimace or frown, } \\
\text { withdrawn, distressed }\end{array}$ & $\begin{array}{l}\text { Frequent to constant frown, } \\
\text { clenched jaw, quivering chin }\end{array}$ \\
\hline Legs & $\begin{array}{l}0 \\
\text { Normal position } \\
\text { or relaxed }\end{array}$ & $\begin{array}{c}1 \\
\text { Uneasy, restless, tense }\end{array}$ & $\begin{array}{c}2 \\
\text { Kicking } \\
\text { Or } \\
\text { Legs drawn up }\end{array}$ \\
\hline Activity & $\begin{array}{c}0 \\
\text { Lying quietly } \\
\text { Normal position } \\
\text { Moves easily }\end{array}$ & $\begin{array}{c}1 \\
\text { Squirming } \\
\text { Shifting back/forth } \\
\text { Tense }\end{array}$ & $\begin{array}{l}2 \\
\text { Arched } \\
\text { Rigid } \\
\text { Or } \\
\text { Jerking }\end{array}$ \\
\hline Cry & $\begin{array}{c}0 \\
\text { No cry } \\
\text { (awake or asleep) }\end{array}$ & $\begin{array}{c}1 \\
\text { Moans or whimpers } \\
\text { Occasional complaint }\end{array}$ & $\begin{array}{l}\text { 2 } \\
\text { Crying steadily } \\
\text { Screams or sobs } \\
\text { Frequent complaints }\end{array}$ \\
\hline Consolability & $\begin{array}{c}0 \\
\text { Content } \\
\text { Relaxed }\end{array}$ & $\begin{array}{c}1 \\
\text { Reassured by occasional } \\
\text { touching, hugging, or "talking to" } \\
\text { Distractible }\end{array}$ & $\begin{array}{c}2 \\
\text { Difficult to console or comfort }\end{array}$ \\
\hline \multicolumn{4}{|c|}{$\begin{array}{l}\text { The FLACC is a behaviour pain assessment scale for use in non-verbal patients unable to provide reports of pain. } \\
\text { Instructions: } \\
\text { 1. Rate patient in each of the five measurement categories } \\
\text { 2. Add together } \\
\text { 3. Document total pain score }\end{array}$} \\
\hline
\end{tabular}

Fig. 2. Face, Legs, Activity, Cry, Consolability (FLACC) scale.

to be used. However, we advocate that undesirable side effects related to the use of the stent and diversion should be eliminated.

The ZUS is a urethral stent designed to drain the bladder after hypospadias and epispadias repairs. Stents were designed with diameters of $6 \mathrm{~F}, 8 \mathrm{~F}$, and $10 \mathrm{~F}$ according to the width of the urethra, and are $12 \mathrm{~cm}$ in length. It is suggested that the stent should be advanced to the front of the external urethral meatus and fixed with an absorbable suture to the glans penis. The stent should be spontaneously removed

\begin{tabular}{|c|c|c|c|c|}
\hline & Total & Group 1 & Group 2 & $\mathbf{p}$ \\
\hline Age & $3.38 \pm 0.12$ & $3.42 \pm 0.17$ & $3.35 \pm 0.16$ & 0.829 \\
\hline $\begin{array}{l}\text { Fistula on the 15th } \\
\text { day }\end{array}$ & $5(6.4 \%)$ & $2(6.4 \%)$ & $3(6.5 \%)$ & 0.990 \\
\hline $\begin{array}{l}\text { Fistula on the 6th } \\
\text { month }\end{array}$ & 12 (15.5\%) & $5(16.1 \%)$ & $7(15.2 \%)$ & 0.914 \\
\hline $\begin{array}{l}\text { Meatal stenosis on } \\
\text { the 6th month }\end{array}$ & $3(3.8 \%)$ & $1(3.2 \%)$ & $2(4.3 \%)$ & 0.804 \\
\hline FLACC 1 (PO Day 1) & $6.06 \pm 0.10$ & $6.10 \pm 0.16$ & $6.04 \pm 0.14$ & 0.760 \\
\hline FLACC 2 (PO Day 3) & $2.88 \pm 0.09$ & $2.52 \pm 0.13$ & $3.13 \pm 0.11$ & 0.001 \\
\hline
\end{tabular}

with urination at the end of the healing process, after four to seven days.

Studies show that the use of a silicone catheter causes cuffing formation, and the neo-urethral was damaged during removal of the catheter. ${ }^{13}$ When the use of a latex Foley catheter was compared with silicone catheters, they caused less cuffing formation, but obstruction and anaphylaxis occurred. ${ }^{13,14}$ We observed that it did not cause the cuffing formation because the ZUS used in our study did not have a balloon and reservoir. Stent occlusion or allergic reaction did not occur in any of the cases.

Leclair et al reported that postoperative care was provided easily after hypospadias repair without the use of a stent, and catheter-induced morbidity was prevented. ${ }^{10} \mathrm{In}$ the same manner, based on objective data from the FLACC pain scale system in our study, we consider that morbidity was prevented on the third postoperative day in patients with the feeding tube compared to the patients with the stent. The patients were happier because they did not have to carry a urine bag and continued physiological urination. This situation was supported by the pain scale.

The most common complications after TIPU operations are reported as fistula formation and meatal stenosis. These complications were especially observed in the first six 
Ozcan et al.

months after surgery. ${ }^{15,16}$ The respective rates of these complications were $16.1 \%$ and $3.2 \%$ in the patients with ZUS, and $15.2 \%$ and $4.3 \%$ in the patients with the feeding tube. These rates are similar to those in the literature. This result suggests that the intended purposes of using urinary diversion have been provided with the use of the ZUS.

The small number of patients was the most important limitaion. Furthermore, the price of the ZUS is higher than that of other diversion tools. This situation requires a costeffectiveness analysis to be undertaken. Nevertheless, our study is the first to present hypospadias surgery results with this new product. The six-month followup period would provide a sufficient contribution for the determination of late complications. We believe that our study could lead to prospective, randomized, controlled studies in the future.

\section{Conclusion}

When the ZUS is compared with the feeding tube in hypospadias repair, it does not make any contribution to the urinary fistula rates. However, ZUS may have an advantage in terms of patient comfort in the postoperative followup. Prospective, randomized trials are needed to assess the efficacy and cost.

Competing interests: The authors report no competing personal or financial interests.

This paper has been peer-reviewed.

\section{References}

1. Snodgrass WT, Lorenzo A. Tubularized incised plate urethroplasty for proximal hypospadias. BJU Int 2002;89:9093. https://doi.org/10.1046/j.1464-410x.2002.02524.x

2. Oesterling JE, Gearhart JP, Jeffs RD. Urinary diversion in hypospadias surgery. Pediatr Urol 1987;29:513-6.

3. Polat $\mathrm{H}$, Yucel $M O$, Cift A, et al. The use of latex Foley catheter in repair of hypospadias the most common seen congenital penile anomaly. Int I Clin Exp Med 2015;8:13421-23.

4. Witjes JA, Del Popolo G, Marberger M, et al. A multicentre, double-blind, randomized, parallel group study comparing polyvinyl chloride and polyvinyl chloride-free catheter materials. J Urol 2009;182:2794-8. hitps://doi.org/10.1016/i.juro.2009.08.047

5. Iddiq DM, Darouiche RO. New strategies to prevent catheter-associated urinary tract infections. Nat Rev Urol 2012;9:305-14. https://doi.org/10.1038/nrurol.2012.68

6. Gall 0, Champigneulle B, Schweitzer B, et al. Postoperative pain assessment in children: A pilot study of the usefulness of the analgesia nociception index. Br J Anaesth 2015;115:890-5. https://doi.org/10.1093/bja/aev361

7. Cohen LL, Martin SR, Gamwell KL, et al. Behavioural techniques to optimize success of in-office pediatric tympanostomy tube placement without sedation. Int I Pediatr Otorhinolaryngol 2015;79:2170-3. https://doi.org/10.1016/i.iporl.2015.09.041

8. Bai J, Jiang N. Where are we: A systematic evaluation of the psychometric properties of pain assessment scales for use in Chinese children. Pain Manag Nurs 2015;16:617-31. https://doi.org/10.1016/i. pmn.2014.11.003

9. Karakan T, Bagcioglu M, Germiyanoglu C. History of hypospadias. Turk Urol Sem 2011;2:162-9. https://doi.org/10.5152/tus.2011.33

10. Leclair M-D, Camby C, Battisti S, et al. Unstented tubularized incised plate urethroplasty combined with foreskin reconstruction for distal hypospadias. Eur Urol 2004;46:526-30. https://doi.org/10.1016/i. eururo.2004.04.021

11. Fang Y-Q, Li T-C, Si T-J, et al. Antibiotic prophylaxis at time of catheter removal following laparoscopic radical prostatectomy: A prospective randomized study. Acta Medica Mediterranea 2014;30:161-5.

12. Mitchell ME, Kulb TB. Hypospadias repair without a bladder drainage catheter. J Urol 1986;135:321-3.

13. Parkin J, Scanlan J, Woolley $M$, et al. Urinary catheter "deflation cuff" formation: Clinical audit and quantitative in vitro analysis. BJU Int 2002;90:666-71. https://doi.org/10.1046/j.1464-410X.2002.03014.x

14. Lieberman P. Anaphylactic reactions during surgical and medical procedures. J Allergy Clin Immunol 2002;1 10:64-9. https://doi.org/10.1067/mai.2002.124970

15. Borer JG, Bauer SB, Peters $C A$, et al. Tubularized incised plate urethroplasty: Expanded use in primary and repeat surgery for hypospadias. J Urol 2001;165:581-5. https://doi.org/10.1097/00005392200102000-00075

16. Elbakry A. Further experience with the tubularized, incised urethral plate technique for hypospadias repair. BJU Int 2002;89:291-4. https://doi.org/10.1046/i.1464-4096.2001.01525.x

Correspondence: Dr. Murat Bagcioglu, Kafkas University, Faculty of Medicine, Urology Department, Kars, Turkey; dr.muratbagcioglu@hotmail.com 